\title{
Thermoplastic/Natural Filler Composites: A Short Review
}

\author{
Nor Fasihah Zaaba and Hanafi Ismail ${ }^{*}$ \\ School of Materials and Mineral Resources Engineering, Universiti Sains Malaysia, \\ Engineering Campus, 14300 Nibong Tebal, Pulau Pinang, Malaysia \\ *Corresponding author: ihanafi@usm.my
}

Published online: 15 February 2019

To cite this article: Zaaba, N. F. \& Ismail, H. (2019). Thermoplastic/natural filler composites: A short review. J. Phys. Sci., 30(Supp. 1), 81-99, https://doi.org/10.21315/ jps2019.30.s1.5

To link to this article: https://doi.org/10.21315/jps2019.30.s1.5

\begin{abstract}
Plastics have many benefits due to their light weight, cost effectiveness, durability and other advantages. They are used as agricultural films, packaging, disposal consumer items, health, construction, etc. However, most plastics are not degradable which cause serious environmental problem. Addition of natural fillers into thermoplastics not only reduce the cost of the thermoplastic/natural filler composites but also help in reducing the waste of non-degradable plastic composite materials in the environment. Present short review deals with the issue of non-degradable plastic materials and the application of various natural fillers in thermoplastic composites. The chemical modifications including compatibilisation and radiation are reviewed and discussed.
\end{abstract}

Keywords: Thermoplastic, natural filler, chemical modification, composites, plastic materials

\section{INTRODUCTION}

Since the development of countless routes for the production of polymers from petrochemical sources, the plastic industry has been developing substantially. Plastics have considerable advantages especially in terms of their durability, low weight and low cost compared to other materials. ${ }^{1,2}$ Currently, almost $50 \%$ of plastic materials is consumed for single-use disposable applications including packaging, agricultural films, disposable consumer items as well as long-term infrastructure such as cable pipes, coatings and structural materials. ${ }^{3}$ Plastic longevity in the environment is not known with certainty since plastics have only been massproduced for around 60 years. Most types of plastic are not degradable or taking 
thousands of years to degrade depending on local environmental factors such as oxygen, temperature and ultraviolet light exposure ${ }^{4-7}$ Because of that, solid waste is becoming a critical issue globally especially in the 21 st century. ${ }^{8}$

In view of that, community attentiveness is presently being engaged on the environmental friendly composite materials manufactured from natural fillers and polymeric materials. ${ }^{9}$ The development of these environmental friendly composite materials have accelerated rapidly since they are nontoxic, biodegradable and safer to deal with. ${ }^{10}$ Environmental friendly composite materials also known as biocomposites are derived from one or more phases that derived from a biological origin. The addition of plant fibres/fillers such as hemp, flax, wood, cotton or food crops as natural filler is important to impart reinforcement. ${ }^{11}$ Besides, the addition of natural filler into composite material offers numerous environmental advantages such as biodegradability, lower density, lower cost, enhance toughness and energy recovery, reduce pollutant emission and reduce the consumption of non-renewable sources. ${ }^{12-14}$

\section{THERMOPLASTICS}

Among the polyolefins, polypropylene (PP) was the first synthetic stereoregular polymer to meet industrial requirement. It is presently the fastest emerging resource for mechanical finish products which are low cost and exhibit high tensile strength. As early as 1869 , Berthelot was the first person who has polymerised PP by reaction with concentrated sulfuric acid. At room temperature, the resulting viscous oil did not exhibit fascinating properties for industrial applications. In 1955, Natta et al. polymerised the crystalline high molecular weight PP from organo-metallic catalysts based on titanium and aluminium which was important for industrial purposes. ${ }^{15} \mathrm{PP}$ is a thermoplastic and belongs to semicrystalline group. Its crystallinity can be seen from its opaque colour of the PP product. PP is resistant to different chemical solvents, bases and acids. ${ }^{16-18}$

In the United States, approximately 5 billion pounds of PP plastic packaging were produced in 2010. The tensile strength and melting point of PP make it the single most used plastic products. However, the problems of decontamination and eliminating odour and stain of PP products make PP one of the slightest recycled post-consumer plastics according to PP production and recycling by the American Chemistry Council. Therefore, manufacturers have carried out "life cycle" educations which study about the plastic from the production of raw material until the waste management stage. This is important to evaluate the sustainability of the final product. 
Thus, studies have been carried out to discover the opportunity of consuming natural fillers as a reinforcing agent in thermoplastic composites. ${ }^{18-20}$ Nevertheless, a reduction of the mechanical properties has been reported when the natural filler incorporated in the synthetic polymer as a minor constituent. In most natural filler composites, the incompatibility of the hydrophobic polymer matrix and the hydrophilic natural filler results in the weak bonding between the components. ${ }^{21}$ Incompatibility of the components leads to agglomeration of fillers during processing, poor dispersion of fillers into the matrix, and poor resistance to moisture, which reduces the use of natural fillers in polymer matrix. ${ }^{17}$

\subsection{Structure}

Three possible arrangements form polymerisation of non-symmetrical propylene molecule $\mathrm{CH}_{2}=\mathrm{CHCH}_{3}$ can be seen from Figure 2 .

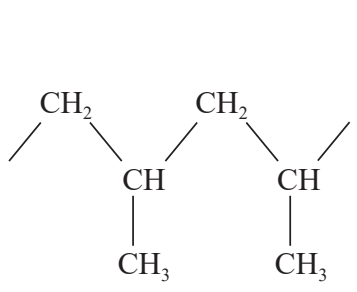

(a)

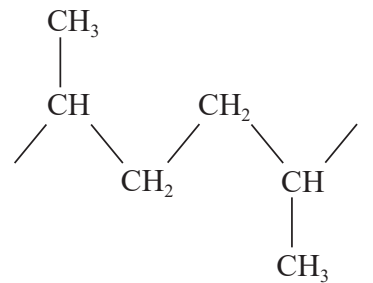

(b)

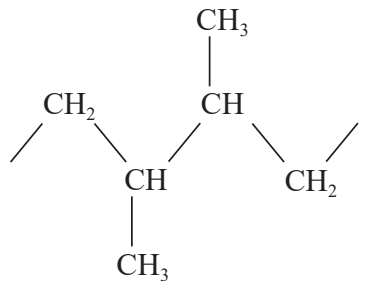

(c)

Figure 2: Isomerism for positions in PP for (a) head-to-tail, (b) head-to-head and (c) tailto-tail. Adapted from http://www.pslc.ws/macrog/pp.htm.

A high chemical regularity of the PP chain and the steric effect of the methyl group highly prefers the head-to-tail arrangement. This is because the occurrences of head-to-head and tail-to-tail arrangement lead to chemical defects along the PP chain. Besides that, a random copolymerisation of PP with a co-monomer induces anticipated chemical defects along the chain as well. Commonly, ethylene is used as the co-monomer. Ethylene element intensely alters the physical properties of the polymer chain such as crystallisation, thermal stability, stiffness and elongation at break. ${ }^{16}$

\section{PROPERTIES AND APPLICATION}

Generally, the variability of existing PP grades is broader than other plastic materials. The average molecular weight is varied from $200,000 \mathrm{~g} \mathrm{~mol}^{-1}$ to $600,000 \mathrm{~g} \mathrm{~mol}^{-1}$. The glass transition temperature of $\mathrm{PP}$ is $0^{\circ} \mathrm{C}$ while the crystalline melting point ranges from $160^{\circ} \mathrm{C}$ to $165^{\circ} \mathrm{C}$. PP has lower water absorption and 
permeability while exhibiting highly chemically resistant because of its non-polar structure. PP is extensively injected to form parts such as bumpers and dashboards in the automotive industry. Profiles, pipes and sheets can be obtained from extrusion while packaging via blow molding. Besides that, the high molecular weight product can be produced by melt spinning. A single PP is not capable to optimise the processability and properties of the final product. Therefore, it is required to control the polymerisation parameters during processing. ${ }^{16}$

PP has a variety of usages, including carpet fibres, clear film packaging, housewares, rope, stationary, loudspeakers, banknotes, reusable containers, automotive components, laboratory equipment and thermal underwear. While for recycled PP, owing to its inherent flexibility, it can be recycled into many different products such as clothing fibres, industrial fibres, containers, dishware, compost bins, speed humps and gardening apparatus labelling (compost bins, garden edging and plant pots).

\section{THERMOPLASTIC/NATURAL FILLER COMPOSITES}

Present attention in reducing the environmental effect of plastic materials is heading to the development of novel plastic products or materials. Likewise, owing to the deficiency of petroleum sources and stress for decreasing the dependence on petroleum materials, there is a growing consideration in manipulating the usage of renewable materials. One of the fascinating approaches to develop the properties of the polymer composites is by the addition of reinforcements such as natural filler which can express to significant necessities of most engineering applications. ${ }^{22}$ For that reason, over the past few years, the anxiety for natural filler reinforced composites have been enhanced drastically for various commercial applications. ${ }^{23-26}$

In fact, the addition of natural fillers with thermoplastic was becoming one of the biggest areas of research. ${ }^{27-29}$ Indeed, the addition of natural fillers to thermoplastics can certainly reduce the cost of the final product. In some way, it can increase the performance of the final product. ${ }^{30}$ Additionally, most of the researchers concentrated on improving the final properties of this thermoplastic/ natural filler plastic product by using additives such as compatibiliser, coupling agent or chemical treatment. As reported by Ragunathan et al. in their previous study on the compatibilising effect of PP maleic anhydride (PPMAH) on PP/ acrylonitrile butadiene rubber (NBR)/palm kernel shell (PKS) composites, the results showed that higher tensile strength and tensile modulus were obtained for compatibilised composites compared with uncompatibilised composites. ${ }^{18}$ Apart from that, Reddy and Yang found that the developed soy protein-jute fibre composites exhibited a relatively high tensile strength and modulus. ${ }^{31}$ 
Even though natural fillers are not as popular as mineral or inorganic fillers, it has some advantages compared with reinforcing materials and traditional fillers. The major advantages of consuming lignocellulosic fillers as fillers/reinforcements in plastics are being low cost, biodegradable, non-abrasive, low densities, low energy consumption, and are easily recyclable. The exploitation of these types of filler as reinforcing components in polymer composites is an effective way to produce an eco-friendly and naturally degradable composites without affecting its rigidity. ${ }^{32}$ Besides that, owing to their renewability, ease of separation, carbon dioxide sequestration and non-abrasive to equipment, natural fillers have attracted an increasing research interest as well. . $^{19,33,34}$

Furthermore, the consumption of high loading fillers tends to increase the stiffness. In the United States, the thermoplastic/natural filler composites have been applied on rail and decking products. While in Europe, they are more prominent in automotive applications such as dashboard, car roofs, seat panels, interior panels, headliners, acoustic panels and parcel shelves. Besides, the thermoplastic/natural filler composites are starting to integrate into pallets, doors and architectural moldings especially in China and other parts of Asia. Indeed, many applications have been paying attention on the use of natural polymers which are inexpensive, renewable and also biodegradable. ${ }^{35-37}$ Efforts are ongoing to determine unconventional resources for biopolymers. Corn stover, wheat straw and cotton stalk, soy protein as well as wheat gluten are among the agricultural by products and agricultural coproducts that have been explored for their potential use as a matrix. ${ }^{31}$

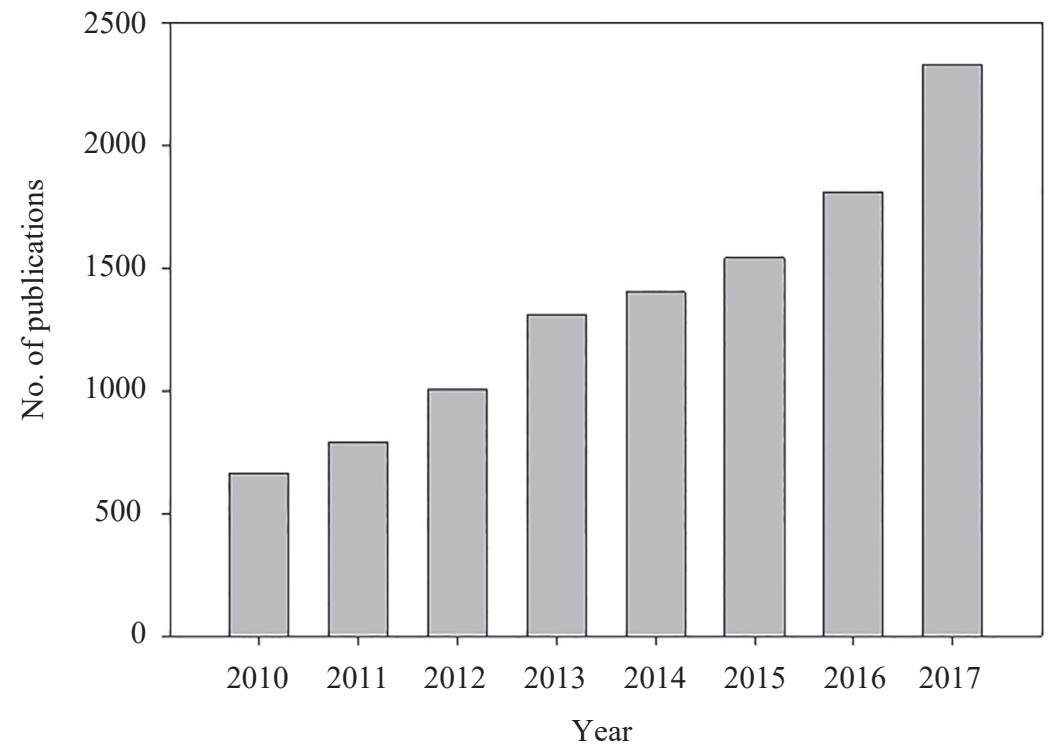

Figure 3: Number of journal publications on the natural fillers and polymer composites (source: www.sciencedirect.com). 
The increasing number of publications during the latest years imitates the growing reputation of this type of composites. Figure 3 shows the number of journal publications on the natural fillers and polymer composites from the year of 2010 to 2017. So far, studies have founded a rough indication of the increased interest of researchers on this topic. The natural fillers which have been reported in literature to reinforce different polymer matrices are listed in Table 1.

Table 1: Recent reported work on natural fillers and polymer composites (source: www. sciencedirect.com).

\begin{tabular}{llc}
\hline Filler & Matrix & References \\
\hline Wheat straw & Recycled PP & 37 \\
Palm kernel shell & PP & 18 \\
Wood chips & Recycled polyethylene & 35 \\
Wood & High density polyethylene & 36 \\
Rice husk & Polyethylene & 38 \\
Rice husk & Recycled high density polyethylene & 17 \\
Rice husk & Recycled high density polyethylene & 39 \\
Wood & PP & 40 \\
\hline
\end{tabular}

\subsection{Challenges}

There are a few crucial drawbacks of the usage of the lignocellulosic filler that limit its applications. The main problem is the compatibility between the high hydrophilic nature of natural fillers and the hydrophobic thermoplastic in composites. ${ }^{38-40}$ The mechanical properties of composites are depending strongly on the interfacial adhesion between filler and matrix components. However, this can be solved by enhancing the adhesion and interaction between fillers and matrix..$^{22,41}$ The first approach that can be used to improve the interfacial adhesion is by using coupling agents. Coupling agents can modify the polymer matrix and enhance the interfacial strength and mechanical properties of the products. Apart from that, filler treatment before mixing process also can be used to improve the interfacial adhesion. ${ }^{42}$ Since the presence of hydroxyl groups in lignin and cellulose, natural fillers have a decent potential for chemical treatment. Hydroxyl groups reaction able to alter the polarity and surface energy of the natural fillers. ${ }^{43}$

Besides that, the possibility of lignocellulosic to degrade and volatile emissions during processing also limit its applications. Consequently, the processing temperature should be limited to $200^{\circ} \mathrm{C}$. Due to these problems, the types of thermoplastics that can be used are also limited. For instance, only polyethylene, $\mathrm{PP}$ or polystyrene can be used in processing with natural fillers. 
Another drawback is the high moisture absorption of the natural fillers due to the high hydroxyl groups in lignocellulosic. This results in fillers swelling and finally affected the properties of composites. ${ }^{42,43}$ Nevertheless, the moisture absorption of the fillers can be lessened through chemical modification of hydroxyl groups present in the fillers. ${ }^{44,45}$ Moreover, there are also some other difficulties accessible by thermoplastic/natural filler composites such as poor weathering resistance, huge inconsistency of mechanical properties, lower elongation at break, lower ultimate strength, and bubbles in the final product. ${ }^{46,47}$

\subsection{Current Developments}

The global markets have indicated increasing demands for bio-based and natural fillers. In the United States, the usage of fillers in plastic industry in 1967 was about 525,000 tons. In 1998, the usage had increased to $1,925,000$ tons. ${ }^{48}$ While in 2010 , 8.5 billion pounds of fillers had been used by plastic industry, with 0.7 billion pounds made up of natural fillers. Figure 4 presents the (a) application areas and (b) countries share for thermoplastic/natural filler composites. Obviously, from Figure 4(a), the leading application areas of thermoplastic/natural filler composites are in building products such as park benches, railing, decking, cladding fencing, roofing and siding.

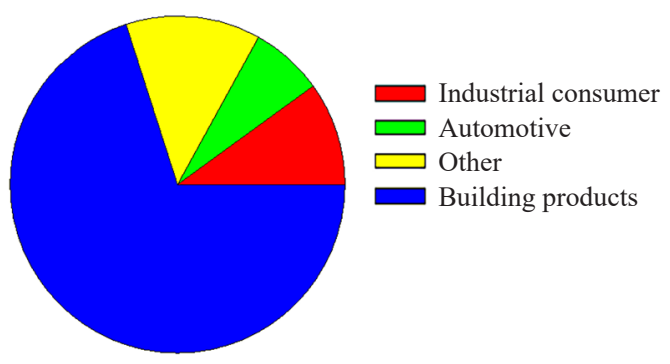

(a)

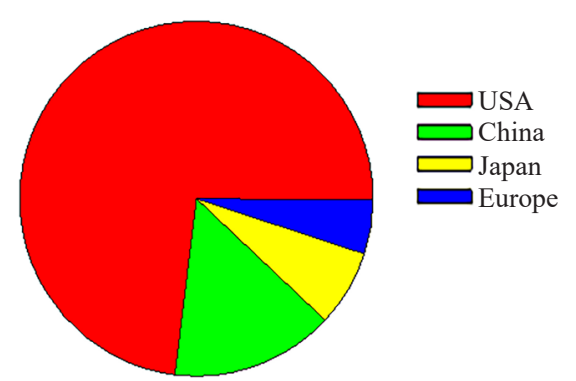

(b)

Figure 4: Illustrations of (a) application areas and (b) countries share for thermoplastic/ natural filler composites (adapted from www.intechopen.com). 


\subsection{Structure and Chemistry}

The structure of lignocellulose is shown in Figure 5. The main component of lignocellulose is a beta(1-4)-linked chain of glucose molecules which is also known as cellulose. The crystalline cellulose is resistance to degradation which is contributed by hydrogen bonds between different layers of the polysaccharides. Besides that, the second most abundant constituent of lignocellulose is hemicellulose which consists of various 5- and 6-carbon sugars such as glucose, mannose, arabinose, galactose and xylose. Lignin comprises three main phenolic components, namely sinapyl alcohol (S), coniferyl alcohol (G) and p-coumaryl alcohol $(\mathrm{H})$. The polymerisation of these three components synthesised lignin. The ratio of these components varies within different plants, cell wall layers and wood tissues. Microfibrils are formed by cellulose, hemicellulose and lignin. Its macrofibrils structure facilitates structural stability in the plant cell wall. ${ }^{49}$

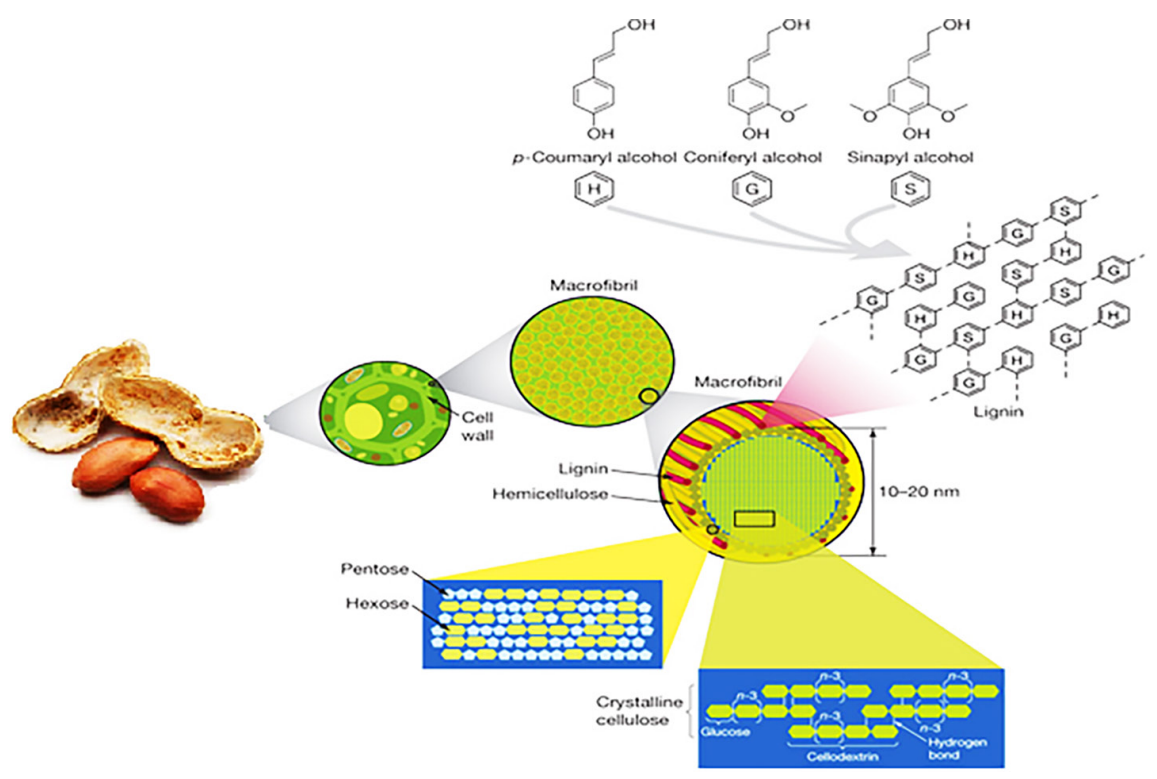

Figure 5: Structure of lignocellulose (adapted from www.nature.com).

Membrane of the cell wall in fillers is not homogeneous. It is complex and built up with layered structures. Figure 6 shows the molecular structure of cellulose. As can be seen from Figure 6, the layered structures comprise a primary wall that is the first layer positioned through cell growth surrounding by three layers of secondary wall. The mechanical properties of the fillers are controlled by this thick central layer of secondary walls. The long chain of cellulose molecules forms a series of helically wound cellular microfibrils which are completed as middle layer. 


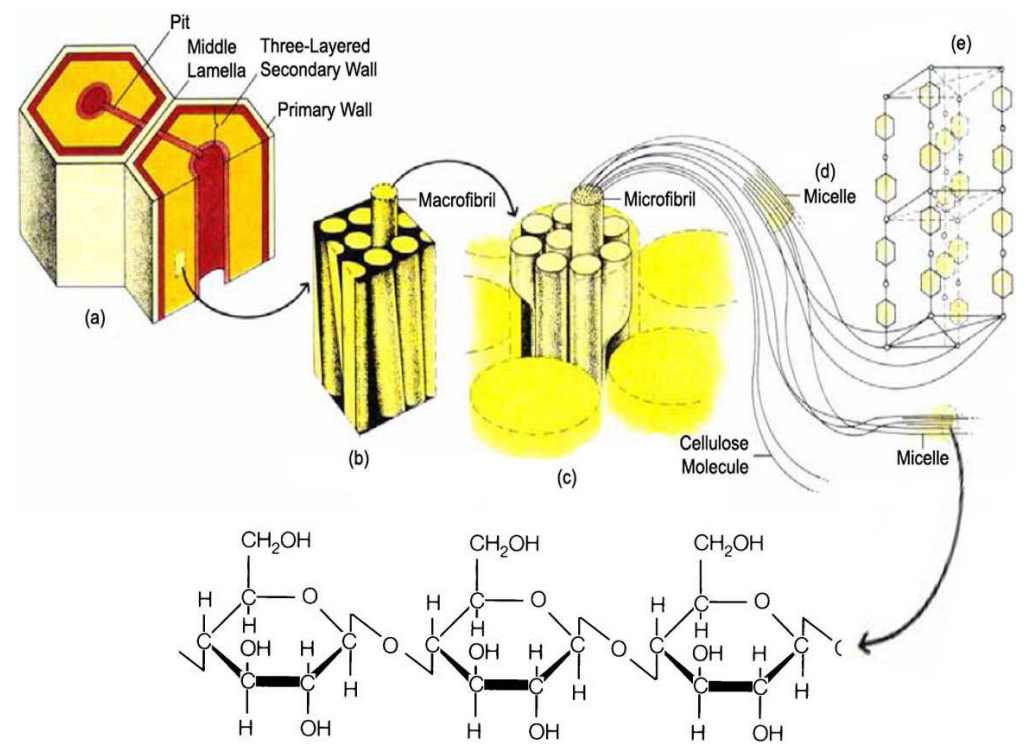

Figure 6: Structure of lignocellulose (adapted from www.nature.com).

Figure 7 shows the positioning of the cellulose fibrils in lignocellulose. The outer secondary cell wall (S1) contains four to six lamellae which are twisting in reverse orders along the longitudinal axis of the tracheid. The thickness of S1 is similar to the primary wall, while the thickness of the middle secondary wall (S2) is slightly smaller than S1. Furthermore, the tertiary wall or inner secondary wall (S3) is infrequently well developed and have little technical significance. Conversely, the microfibril orientation contained by S2 layer has strong influence on mechanical properties of fillers such as elasticity and modulus. The microfibril angle and cellulose content determine the mechanical properties of fillers. A capable reinforcing filler should has high cellulose content and low microfibril angle. ${ }^{50}$

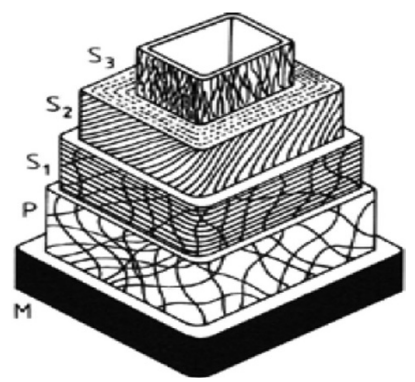

Figure 7: Positioning of the cellulose fibrils in lignocellulose, showing middle lamella (M), primary wall (P), secondary wall (S1), secondary wall II (S2), and secondary wall III (S3). Adapted from www.nature.com. 


\subsection{Properties and Application}

Natural fillers display significant deviation in diameter along with the length of separate filaments. The properties of the individual constituents, the lamella matrix and the fibrillar structure affect the strength characteristics of fillers, while the quality of the fillers is dependant upon, maturity and processing methods of the filler's extraction. Apart from that, electrical resistivity, density, initial modulus and ultimate tensile strength are correlated to the chemical composition and internal structure of fillers. Moreover, the overall properties of the fillers can be determined from the main variables such as the cell dimensions, microfibrillar angle, structure and defects of the fillers. ${ }^{51,52}$

\subsection{Chemical Modification}

Natural fillers can be modified since they are made up of hydroxyl groups from cellulose and lignin. However, due to the involvement of hydroxyl groups in hydrogen bonding within the cellulose molecules, the effectiveness or the interfaces of natural fillers towards the matrix may decrease. Mechanical, thermal and physical properties of composites are depending on the interfaces. Thus, chemical/physical treatments or specific interfacial additives can be added to improve the interfacial adhesion by activating these groups. Besides, it provides the new moieties that can efficiently interconnect between the polymer matrix and the fillers. ${ }^{18,53,54}$ In addition, $\mathrm{NaOH}$ (delignation and bleaching) or traditional chemical treatments such as extraction with benzene and alcohol can also be used. Different chemical modifications of natural fillers will result in different levels of achievement in enhancing strength, fitness and adhesion between the fillers and the matrix. ${ }^{17}$ Brief explanations of some substantial chemical modifications of natural filler which applied in this research are discussed in the subsequent sections.

\subsubsection{Compatibilisation with PEAA}

Poly(ethylene-co-acrylic acid) (PEAA), also known as carboxylated ethylene copolymer, is produced at high pressure via free radical copolymerisation of ethylene and acrylic acid. ${ }^{55}$ The principal monomers, ethylene and acrylic acid influence the properties of PEAA copolymers. Many olefinic polymers comprise of ethylene as a basic monomer. Polyethylene is hydrophobic in nature which is composed of only carbon and hydrogen. Under suitable circumstances, its symmetric structure allows it to crystallise. While for acrylic acid, the pendant carboxylic acid group allows it to absorb water although it also has a backbone of carbon and hydrogen. During polymerisation, hydrogen groups opposite the acrylic acid group tend to backbite, hence imparting itself to branching. ${ }^{56,57}$ 
Free radicals of the cellulose molecules may initiate the acrylation reaction. High energy radiation can be used to treat cellulose, hence generate radicals and chain scission..$^{58}$ In natural fillers surface modification, acrylations lead to strong covalent bond formation, thus slightly increase the tensile strength and Young's modulus of treated fillers..$^{59,60}$ Scheme 1 shows the whole reaction between cellulose-OH groups and acrylic acid from PEAA. ${ }^{51}$

$$
\text { Fillers- } \mathrm{OH}+\mathrm{CH}_{2} \mathrm{CH}-\mathrm{COOH} \longrightarrow \text { Fillers-O-CO-CH-CH}{ }_{2}+\mathrm{H}_{2} \mathrm{O}
$$

Scheme 1

\subsubsection{Filler Modification by Polyvinyl Alcohol}

The first polyvinyl alcohol (PVOH) was prepared by Hermann and Haehnel via hydrolysing polyvinyl acetate in potassium hydroxide and ethanol. Generally, $\mathrm{PVOH}$ is produced using a continuous process from polyvinyl acetate. ${ }^{61}$ In the presence of aqueous sodium hydroxide or anhydrous sodium methylate, acetate groups are hydrolysing using ester exchange with methanol. To determine its specific functional uses and physical characteristics, the degrees of hydrolysis and polymerisation are prominent. PVOH is a powder with white or cream coloured, translucent, odourless and tasteless. The $\mathrm{PVOH}$ in food supplement tablets acts as a moisture barrier. Likewise, PVOH can be used in natural fillers modification in natural filler/thermoplastic composites application. This is due to the hydrophilic nature of PVOH. It has a hydroxyl group on each of its repeating units, hence promoting the interaction of hydrogen bonds with hydroxyl and carboxyl groups of cellulose fillers. Scheme 2 shows a result of filler treatment by PVOH.

Fillers- $\mathrm{OH}+\mathrm{CH}_{2}-\mathrm{CH}-\mathrm{OH} \longrightarrow$ Fillers-O-CHCH$+\mathrm{H}_{2} \mathrm{O}$

Scheme 2

\subsubsection{Alkaline Peroxide Pre-treatment}

Alkaline peroxide pre-treatment is one of the significant modifications of natural fillers by interference of hydrogen bonding in the network structure. Throughout this treatment, celluloses are depolymerised and short length crystallites are exposed. Then, some quantity of oils, wax and lignin that are protecting the external surface of the fillers cell wall are removed. ${ }^{62}$ The addition of aqueous sodium hydroxide $(\mathrm{NaOH})$ to natural fillers permits the ionisation of hydroxyl groups to alkoxide. ${ }^{63}$ Consequently, the exposure of celluloses on the filler's surface is increased and mechanical interlocking is improved. ${ }^{17}$ This means that 
the number of possible reaction sites are increased, thus promoting natural filler's wetting. Moreover, many studies on alkaline treatments have been done in order to increase the mechanical properties of polymer composites. For example, Bledzki and Gassan examined the effect of alkali treatment on properties of hybrid filler composites. ${ }^{58}$ The results presented that alkali treatment manages to rise the fillers surface area effectiveness in contacting the polymer matrix by breaking the fillers bundle into smaller size of fillers. Likewise, Sreekala et al. and Sreekala et al. reported findings that the interfibrillar region becomes less dense and less rigid after the partial removal of lignin and hemicellulose by alkali modification of cellulose fillers. ${ }^{59,60}$ Scheme 3 shows a result of alkaline treatment. ${ }^{64}$

$$
\text { Fillers- } \mathrm{OH}+\mathrm{NaOH} \longrightarrow \text { Fillers- } \mathrm{O}^{-} \mathrm{Na}^{+}+\mathrm{H}_{2} \mathrm{O}
$$

Scheme 3

\subsubsection{Radiation on Thermoplastic/Natural Filler Composites}

Instead of using chemical modification on thermoplastic/natural filler composites to improve the interfacial adhesion between natural fillers and polymer matrix, one of the most commonly alternative approaches is using radiation technology. Radiation technology is able to introduce changes by breaking the chemical bonds of polymeric materials. Process conditions such as type and dosage of radiation, presence of oxygen, additives, solvents and degree of crystallinity mainly influence the polymer changes. ${ }^{65}$ There are many benefits of ionising radiation on polymer modification. For instances, the process can be carried out at ambient temperature, with no chemical initiator needed, and there is no pollutant and is solvent-free. Besides that, electron beam and cobalt 60 are examples of primary sources providing radioactive elements.

Generally, crosslinking and degradation are two major reactions involved during irradiation process, thus influencing the physical and mechanical properties of the polymeric materials. Due to the limitation of gamma irradiation such as time consuming and probability of severe oxidation degradation of the composites, electron beam irradiation (EBI) offers some advantages in comparison to other conservative alteration methods. ${ }^{66}$ The advantages of EBI include: it provides reliable sterilisation; very high dose rates are achievable; radiation doses are easily controlled; safe and easy to operate; high speed enhancement of properties, allowing irradiation of a variety of physical shapes; and pose no serious environmental hazards due to practically free of waste products. ${ }^{67-69}$ Usually, during EBI, polymers having hydrogen in their monomeric units tend to form crosslink whereas others might be degraded during irradiation. 
Yet, it is also reliant on the microstructure of the certain polymer. The final properties of the material strongly depend on the degree of crosslinks. The crosslinked structure could reduce the interfacial tension and results in an improvement in material properties. Radiation technology is able to alter the structure and chemical composition as well as mechanical and thermal properties. However, the irradiation dosage is required to be maintained at an optimum level in order to prevent excessive crosslinking which can result in material brittleness. Basically, gel content technique can be used to measure the crosslink in materials whereas the radiated materials might be immersed into a solvent. The increment of gel content attributes to the occurrence of crosslinking while the increment of soluble friction indicates the chain scission of polymers. ${ }^{70-72}$

Several reports have revealed that ionising radiation efficiently enhances the material properties by introducing the cross linking and scission process throughout the polymer chains in multipurpose applications. ${ }^{73-75}$ The elongation at break and the intensity of hydrogen and carbonyl stretching group increased with increasing the irradiation dose. ${ }^{77}$ Besides that, Zhai et al. reported in their findings that a chemical reaction happened through irradiation followed by the formation of complete network structure in starch-based plastic sheets. ${ }^{76}$ The tensile strength also increased by electron beam irradiation.

Electron beam radiation can be generated by a heated cathode in a vacuum. The procedure begins with the emitting of electron from the cathode and acceleration between cathode and anode in applied electrostatic field. The acceleration of electron to the window plane of the accelerator can be emphasised by using an optical electron beam system. As stated by Drobny, when the energy is sufficient to penetrate the 5-20 $\mu \mathrm{m}$ thick titanium window of the accelerator, the electrons can leave the vacuum chamber. ${ }^{77}$ After an electron beam entered a material, the accelerated electron can be altered. The large number of interactions such as ionisation, excitation and electron capture causes energy loss.

\section{CONCLUSION}

The utilisation of plastics in various applications such as agriculture, construction, health, household, etc. provides challenges for researchers to find suitable waste management strategies for plastics. Thermoplastic/natural filler composites are cost effective, recyclable and degradable which can reduce the utilisation of synthetic materials in different application of plastics. 


\section{ACKNOWLEDGEMENTS}

The authors would like to acknowledge the financial support provided by Universiti Sains Malaysia Postdoctoral Fellow Scheme.

\section{REFERENCES}

1. Andrady, A. L. \& Neal, M. A. (2009). Applications and societal benefits of plastics. Phil. Trans. R. Soc. B, 364, 1977-1984, https://doi.org/10.1098/rstb.2008.0304.

2. Thompson, R. C. et al. (2009). Our plastic age. Phil. Trans. R. Soc. B, 364, 19731976, https://doi.org/10.1098/rstb.2009.0054.

3. PlasticsEurope. (2008). The compelling facts about plastics: An analysis of plastics production, demand and recovery in Europe. Brussels: PlasticsEurope.

4. Swift, G. \& Wiles, D. (2004). Degradable polymers and plastics in landfill sites. Encycl. Polym. Sci. Technol., 9, 40-51, https://doi.org/10.1002/0471440264. pst457.

5. Zaaba, N. F., Ismail, H. \& Jaafar, M. (2017). A study of the degradation of compatibilized and uncompatibilized peanut shell powder/recycled polypropylene composites due to natural weathering. J. Vin. Add. Technol., 23(4), 290-297, https://doi.org/10.1002/vnl.21504.

6. Zaaba, N. F. \& Ismail, H. (2018). Comparative study of irradiated and nonirradiated recycled polypropylene/peanut shell powder composites under the effects of natural weathering degradation. BioResour., 13(1), 487-505.

7. Sreekanth, M. S. et al. (2009). Effect of particle size and concentration of fly ash on properties of polyester thermoplastic elastomer composites. J. Min. Mater. Char. Eng., 8(3), 237-248, https://doi.org/10.4236/jmmce.2009.83021.

8. Susan, E. M. S., John, D. C. \& Ruben, J. H. (2004). Plastic packaging: Properties, processing, applications and regulations, 2nd ed. Munich: Carl Hanser Verlag.

9. Sarki, J. et al. (2011). Potential of using coconut shell particle fillers in ecocomposite materials. J. Alloy. Comp., 509, 2381-2385, https://doi.org/10.1016/j. jallcom.2010.11.025.

10. Shalwan, A. \& Yousif, B. F. (2013). In state of art: Mechanical and tribological behaviour of polymeric composites based on natural fibres. Mater. Des., 48, 14-24, https://doi.org/10.1016/j.matdes.2012.07.014.

11. Fowler, P. A., Hughes, J. M. \& Elias, R. M. (2006). Biocomposites: Technology, environmental credentials and market forces. J. Sci. Food Agr., 86, 1781-1789, https://doi.org/10.1002/jsfa.2558.

12. Faruk, O. et al. (2012). Biocomposites reinforced with natural fibers: 20002010. Progr. Polym. Sci. 37, 1552-1596, https://doi.org/10.1016/j.progpolymsci. 2012.04.003.

13. Ismail, H., Edyham, M. R. \& Wirjosentono, B. (2002). Bamboo fiber filled natural rubber composites: The effect of filler loading and bonding agents. Polym. Test., 21, 139-144, https://doi.org/10.1016/S0142-9418(01)00060-5. 
14. Imoisili, P. E et al. (2018). Effect of high-frequency microwave radiation on the mechanical properties of plantain (Musa paradisiaca) fibre/epoxy biocomposite. J. Phys. Sci., 29(3), 23-35, https://doi.org/10.21315/jps2018.29.3.3.

15. Natta, G. et al. (1955). 1st example of a crystalline isotactic polypropylene. J. Am. Chem. Soc., 77, 1708-1710, https://doi.org/10.1021/ja01611a109.

16. Karger-Kocsis, J. (1994). Polypropylene structure, blends and composites. Vol. 1: Structure and morphology. Amsterdam: Springer Netherlands.

17. Chen, R. S. et al. (2015). Biocomposites based on rice husk flour and recycled polymer blend: Effects of interfacial modification and high fibre loading. Biores., 10(4), 6872-6885, https://doi.org/10.15376/biores.10.4.6872-6885.

18. Santiagoo, R. et al. (2016). The compatibilizing effect of polypropylene maleic anhydride (PPMAH) on polypropylene (PP)/acrylonitrile butadiene rubber (NBR)/palm kernel shell (PKS) composites. ARPN J. Eng. Appl. Sci., 11(3).

19. Mukherjee, T. \& Kao, N. (2011). PLA based biopolymer reinforced with natural fibre: A review. J. Polym. Environ., 19(3), 714-725, https://doi.org/10.1007/ s10924-011-0320-6.

20. Rahmat, A. R. et al. (2009). Approaches to improve compatibility of starch filled polymer system: A review. Mater. Sci. Eng. C, 29, 2370-2377, https://doi.org/10.1016/j.msec.2009.06.009.

21. Robertson, N. L. M. et al. (2013). Mechanical performance and moisture absorption of various natural fiber reinforced thermoplastic composites. J. Appl. Polym. Sci., 130(2), 969-980, https://doi.org/10.1002/app.39237.

22. Abd. Rajak Hamim, F., Ghani, S. A. and Zainuddin, F. (2017). Influences of the coupling agent and various compatibilisers on properties of recycled high density polyethylene/ethylene vinyl acetate/taro powder (Colocasia esculenta) biocomposites. J. Phys. Sci., 28(2), 71-84, https://doi.org/10.21315/ jps2017.28.2.5.

23. Akil, H. M. et al. (2011). Kenaf fiber reinforced composites: A review. Mater. Des., 32, 4107-4121, https://doi.org/10.1016/j.matdes.2011.04.008.

24. Zaaba, N. F., Ismail, H. \& Jaafar, M. (2016). Recycled polypropylene/peanut shell powder composites: Pre-treatment of lignin using alkaline peroxide. BioRes., 11(2), 3524-3537, https://doi.org/10.15376/biores.11.2.3524-3537.

25. Zaaba, N. F., Ismail, H. \& Jaafar, M. (2017). Recycled polypropylene/peanut shell powder (RPP/PSP) composites: Property comparison before and after electron beam irradiation. Polym. Comp., 39, 3048-3056, https://doi.org/10.1002/ pc. 24309 .

26. Zaaba, N. F., Ismail, H. \& Mariatti, M. (2016). Utilization of polyvinyl alcohol on properties of recycled polypropylene/peanut shell powder composites. Proced. Chem., 19, 763-769, https://doi.org/10.1016/j.proche.2016.03.082.

27. Sanadi, A. R., Caulfield, D. F. \& Rowell, R. M. (1994). Reinforcing polypropylene with natural fibers. Plast. Eng., 50(4), 27-28.

28. Obasi, H. C. (2015). Peanut husk filled polyethylene composites: Effects of filler content and compatibilizer on properties. J. Polym. Environ., Article ID 189289 , 1-9, https://doi.org/10.1155/2015/189289. 
29. Chun, K. S. and Husseinsyah, S. (2014). Agrowaste-based composites from cocoa pod husk and polypropylene: Effect of filler content and chemical treatment. J. Thermopl. Comp. Mater., 29(10), 1332-1351, https://doi.org/10. 1177/0892705714563125.

30. Agunsoye, O. \& Aigbodion, V. S. (2013). Bagasse filled recycled polyethylene bio-composites: Morphological and mechanical properties study. Res. Phys., 3, 187-194, https://doi.org/10.1016/j.rinp.2013.09.003.

31. Reddy, N. \& Yang, Y. (2011). Completely biodegradable soy protein-jute biocomposites developed using water without any chemicals as plasticizer. Ind. Crops Prod., 33, 35-41, https://doi.org/10.1016/j.indcrop.2010.08.007.

32. Majeed, K. et al. (2013). Potential materials for food packaging from nanoclay/ natural fibers filled hybrid composites. Mater. Des., 46, 391-410, https://doi. org/10.1016/j.matdes.2012.10.044.

33. Ku, H. et al. (2011). A review on the tensile properties of natural fiber reinforced polymer composites. Comp. B Eng., 42(4), 856-873, https://doi.org/10.1016/j. compositesb.2011.01.010.

34. Kalia, S., Kaith, B. S. \& Kaur, I. (2009). Pretreatments of natural fibers and their application as reinforcing material in polymer composites - A review. Polym. Eng. Sci., 49, 1253-1272, https://doi.org/10.1002/pen.21328.

35. Zanoaga, M., Tanasa, F. \& Mamunya, Y. (2016). Compatibilized green composites based on wood chips and thermoplastic polymer waste matrices. Cell. Chem. Technol., 50(5), 637-648.

36. Tazi, M. et al. (2016). Effect of wood fillers on the viscoelastic and thermophysical properties of HDPE-wood composite. Int. J. Polym. Sci., Article ID 9032525, https://doi.org/10.1155/2016/9032525.

37. Yu, M. et al. (2016). Hybrid composites from wheat straw, inorganic filler, and recycled polypropylene: Morphology and mechanical and thermal expansion performance. Int. J. Polym. Sci., Article ID 2520670, https://doi.org/ 10.1155/2016/2520670.

38. Arjmandi, R. et al. (2015). Rice husk filled polymer composites. Int. J. Polym. Sci., Article ID 501471, https://doi.org/10.1155/2015/501471.

39. Tong, J. Y. et al. (2014). Study of the mechanical and morphology properties of recycled HDPE composite using rice husk filler. Adv. Mater. Sci. Eng., Article ID 938961, https://doi.org/10.1155/2014/938961.

40. Mattos, B. D. et al. (2014). Properties of polypropylene composites filled with a mixture of household waste of mate-tea and wood particles. Constr. Build. Mater., 61, 60-68, https://doi.org/10.1016/j.conbuildmat.2014.02.022.

41. Hamim, F. A. R., Abdul Ghani, S. \& Zainudin, F. (2016). Properties of recycled high density polyethylene (RHDPE)/ethylene vinyl acetate (EVA) blends: The effect of blends composition and compatibilisers. J. Phys. Sci., 27(2), 23-39, https://doi.org/10.21315/jps2016.27.2.3.

42. Yuan, X., Jayaraman, K. \& Bhattacharyya, D. (2004). Effects of plasma treatment in enhancing the performance of wood fibre-polypropylene composites. Comp. A Appl. Sci. Manuf., 35(12), 1363-1374, https://doi.org/10.1016/j. compositesa.2004.06.023. 
43. Gassan, J. \& Gutowski, V. S. (2000). Effects of corona discharge and UV treatment on the properties of jute-fibre epoxy composites. Comp. Sci. Technol., 60(15), 2857-2863, https://doi.org/10.1016/S0266-3538(00)00168-8.

44. Chang, W. P., Kim, K. J. \& Gupta, R. K. (2009). Moisture absorption behavior of wood/plastic composites made with ultrasound-assisted alkali-treated wood particulates. Comp. Interf., 16 937-951, https://doi.org/10.1163/09276440 9X12477481859067.

45. Huda, M. S. et al. (2008). Effect of fiber surface treatments on the properties of laminated biocomposites from poly(lacticacid) (PLA) and kenaf fibers. Comp. Sci. Technol., 68(2), 424-432, https://doi.org/10.1016/j.compscitech.2007.06.022.

46. Sydenstricker, T. H., Mochnaz, S. \& Amico, S. C. (2003). Pull-out and other evaluations in sisal-reinforced polyester biocomposites. Polym. Test., 22(4), 375380, https://doi.org/10.1016/S0142-9418(02)00116-2.

47. Toriz, G., Denes, F. \& Young, R. A. (2002). Lignin-polypropylene composites. Part 1: Composites from unmodified lignin and polypropylene. Polym. Comp., 23(5), 806-811, https://doi.org/10.1002/pc.10478.

48. Eckert, C. H. (1999). Functional fillers for plastics: Outlook to the year 2005. Paper presented at the Proceedings of the Fifth International Conference on Woodfiber-plastic Composites, Madison, United States.

49. Rubin, E. (2008). Genomics of cellulosic biofuels. Nature, 454, 841-845, https://doi.org/10.1038/nature07190.

50. Williams, G. I. \& Wool, R. P. (2000). Composites from natural fibers and soy oil resins. Appl. Comp. Mater., 7(5), 421-432, https://doi.org/10.1023/ A:1026583404899.

51. Mohanty, A. K., Misra, M. \& Drzal, L. T. (2001). Surface modifications of natural fibers and performance of the resulting biocomposites: An overview. Comp. Interf., 8(5), 313-343, https://doi.org/10.1163/156855401753255422.

52. Célino, A. et al. (2013). The hygroscopic behavior of plant fibers: A review. Front. Chem., 1(43).

53. Nabi Saheb, D. \& Jog, J. P. (1999). Natural fiber polymer composites: A review. Adv. Polym. Technol., 18, 351-363, https://doi.org/10.1002/(SICI)10982329(199924)18:4\%3C351::AID-ADV6\%3E3.0.CO;2-X.

54. George, J., Sreekala, M. S. \& Thomas, S. (2001). A review on interfacial modification and characterization of natural fiber reinforced plastic composites. Polym. Eng. Sci., 41(9), 1471-1485, https://doi.org/10.1002/pen.10846.

55. Wakabayashi, K. \& Register, R. (2005). Micromechanical interpretation of the modulus of ethylene(meth) acrylic acid copolymers. Polym., 46(20), 8838-8845, https://doi.org/10.1016/j.polymer.2004.12.063.

56. Kazayawoko, M., Balatinecz, J. J. \& Matuana, L. M. (1999). Surface modification and adhesion mechanisms in woodfiber-polypropylene composites. J. Mater. Sci., 34(24), 6189-6199, https://doi.org/10.1023/A:1004790409158.

57. McCord, E., Shaw, H. \& Hutchinson, R. (1997). Short-chain branching structures in ethylene copolymers prepared by high-pressure free-radical polymerization: An NMR analysis. Macromol., 30, 246, https://doi.org/10.1021/ma9606871. 
58. Bledzki, A. K. \& Gassan, J. (1999). Composites reinforced with cellulose based fibres. Progr. Polym. Sci., 24(2), 221-274, https://doi.org/10.1016/S0079-6700 (98)00018-5.

59. Sreekala, M. S. et al. (2000). Oil palm fiber reinforced phenol formaldehyde composites: Influence of fiber surface modifications on the mechanical performance. Appl. Comp. Mater., 7, 295-329, https://doi.org/10.1023/A:1026 534006291.

60. Sreekala, M. S., Kumaran, M. G. \& Thomas, S. (2002). Water sorption in oil palm fiber reinforced phenol formaldehyde composites. Comp. A Appl. Sci. Manuf., 33(6), 763-777, https://doi.org/10.1016/S1359-835X(02)00032-5.

61. Haweel, C. K. \& Ammar, S. H. (2008). Preparation of polyvinyl alcohol from local raw material. Iraqi J. Chem. Petrol. Eng., 9(1), 15-21.

62. Li, Y., Mai, Y. W. \& Ye, I. (2000). Sisal fibre and its composites: A review of recent developments. Comp. Sci. Technol., 60(11), 2037-2055, https://doi.org/ 10.1016/S0266-3538(00)00101-9.

63. Agrawal, N. S. et al. (2000). Activation energy and crystallization kinetics of untreated and treated oil palm fiber reinforced phenol formaldehyde composites. Mater. Sci. Eng. A, 277, 77-82, https://doi.org/10.1016/S0921-5093 (99)00556-0.

64. Pothan, L. A., Thomas, S. \& Groeninckx, G. (2006). The role of fiber matrix interaction on the dynamic mechanical properties of chemically modified banana fiber/polyester composites. Comp. A Appl. Sci. Manufact., 37(9), 1260-1269, https://doi.org/10.1016/j.compositesa.2005.09.001.

65. Thayer, D. W. (1990). Food irradiation: Benefits and concerns. J. Food Qual., 13(3), 147-169, https://doi.org/10.1111/j.1745-4557.1990.tb00014.x.

66. Youssef, H. A. et al. (2009). Studies of sugarcane baggase fiber-thermoplastic composites. J. Elast. Plast., 41, 245-262, https://doi.org/10.1177/0095244 308095014.

67. Sam, S. T., Ismail, H. \& Ahmad, Z. (2012). Study on electron beam irradiated linear low density polyethylene/soya powder blends under outdoor exposure. J. Vin. Add. Technol., 18(4), 241-249, https://doi.org/10.1002/vnl.20327.

68. Aji, I. S. et al. (2013). Induced tensile properties with EB-crosslinking of hybridized kenaf/palf reinforced HDPE composite. Pert. J. Sci. Technol., 21(1), 135-140.

69. Mizera, A. et al. (2012). Properties of selected polymers after radiation crosslinking. Int. J. Math. Comp. Sim., 6(6), 592-599.

70. Nordin, R. \& Ismail, H. (2013). Electron beam treatment for enhancing the compatibility, thermal and tensile properties of LLDPE/PVA blends. Part I: Effect of irradiation doses. Int. J. Eng. Res. Appl., 3(6), 1820-1825.

71. Ismail, H., Galpaya, D. \& Ahmad, Z. (2010). Electron beam irradiation of blends of polypropylene with recycled acrylonitrile butadiene rubber. J. Vin. Add. Technol., 16(2), 141-146.

72. Bee, S. T. et al. (2012). Effect of montmorillonite on the electron beam irradiation alumina trihydrate added polyethylene and ethylene vinyl acetate nanocomposite. Polym. Comp., 33, 1883-1892. 
73. Choi, H. Y., Han, S. O. \& Lee, J. S. (2008). Surface morphological, mechanical and thermal characterization of electron beam irradiated fibers. Appl. Surf. Sci., 255, 2466-2473.

74. Khan, F., Ahmad, S. R. \& Kronfli, E. (1999). Stability of jute fibres on exposure to ionising radiation. Polym. Degrad. Stab., 63, 79-84.

75. Alessi, S. et al. (2007). E-beam curing of epoxy-based blends in order to produce high-performance composites. Rad. Phys. Chem., 76, 1308-1311.

76. Zhai, M., Yoshii, F. \& Kume, T. (2003). Syntheses of PVA/starch grafted hydrogels by irradiation. Carb. Polym., 50(3), 311-317.

77. Drobny, J. G. 2006. Modification of polymers by ionizing radiation: A review. Paper presented at the Annual Technical Conference 2006 (ANTEC 2006), 7-11 May, Charlotte, NC. 